\title{
Adaptation and Growth Performance Evaluation of Nitrogen Fixing Tree/Shrub Species in Dello-menna District of Bale Zone, Southeast Ethiopia
}

\author{
Wondmagegn Bekele ${ }^{1,}$, , Bikila Mengistu ${ }^{2}$, Hirpa Abebe ${ }^{1}$, Zerihun Dibaba ${ }^{1}$, Fikru Ameyu ${ }^{1}$ \\ ${ }^{1}$ Oromia Agricultural Research Institute, Sinana Agricultural Research Center, Bale-Robe, Ethiopia \\ ${ }^{2}$ Oromia Agricultural Research Institute, Fitche Agricultural Research Center, North-Shewa, Ethiopia
}

Email address:

wondmagegnb2004@gmail.com (W. Bekele)

${ }^{*}$ Corresponding author

\section{To cite this article:}

Wondmagegn Bekele, Bikila Mengistu, Hirpa Abebe, Zerihun Dibaba, Fikru Ameyu. Adaptation and Growth Performance Evaluation of Nitrogen Fixing Tree/Shrub Species in Dello-menna District of Bale Zone, Southeast Ethiopia. American Journal of Agriculture and Forestry. Vol. 9, No. 3, 2021, pp. 127-130. doi: 10.11648/j.ajaf.20210903.15

Received: March 5, 2021; Accepted: May 11, 2021; Published: May 27, 2021

\begin{abstract}
Prior integration of any tree/shrub species in a given land use system there is always the need of undertaking a field trials for the adaptability and growth performance evaluation for particular environment. Study was designed and conducted to evaluate the adaptability potential and growth performance of six nitrogen fixing tree/shrub species in Dellomenna district of Bale zone, southeast Ethiopia. The considered species in the study are Cajanus cajan, Flemingya macrophylla, Gliricidia sepium, Sesbania sesban, Calliandra calothyrsus and Leucaena leucocephela. Seedlings were produced in a nursery site and transplanted to the experimental site. The experiment was laid out in RCBD design with three replications, and the management practices employed uniformly for each species throughout the stud period. In the study the necessary growth performance data parameters; plant height, root collar diameter and survival rate were measured and recorded. Thereafter, the data was analyzed by GenStat $\left(15^{\text {th }} \mathrm{ed}\right)$ and Excel computerized programs. Results obtained showed that, these growth performance data parameters were significantly $(\mathrm{p}<0.05)$ varied among the tested species. In this respect, Flemingya macrophylla, Sesbania sesban, Gliricidia sepium and Cajanus cajan attain the higher mean values in survival rate, plant height and root collar diameter. While Leucaena leucocephela and Calliandra calothyrsus attain the lowest mean values for the entire growth performance parameters. Hence, it can be inferred that the study site matched well with the environmental requirement of F. macrophylla, S. sesban, G. sepium and C. cajan. The species therefore offers much promise for future use in any of agroforestry practices in the area. However, evaluation of their contribution to soil fertility improvement and crop yield needs to be further investigated as this may insights to know their nutrient provision potential while integrated together with annual and/or perennial plants in agroforestry land use system.
\end{abstract}

Keywords: Agroforestry, Plant Height, Root Collar Diameter, Survival Rate

\section{Introduction}

In sub-Saharan Africa (SSA) expansion and intensification of agricultural lands in effort to feed growing population is the major cause of land degradation and soil fertility [7]. Ethiopia with a population of 94.351 million, is one of the sub-Saharan countries where the problem is becoming serious in many parts of the country [8]. In Southeast Ethiopia, Bale zone has long been known by its wide range of forest resource coverage. However, the resource has been dwindling from time to time due to an over exploitation of the woody and non-woody products by the local community. Indeed, the area is now characterized by soil degradation, habitat fragmentation and biodiversity losses $[2,11,12]$. The integration of woody species in agricultural landscape could reduce the pressure on the surrounding natural forest. For instance, agroforestry, which combine forestry and agriculture, have the capacity to sustain the productivity of farmlands [6]. Moreover, the system could also serve as buffer zone for forest degradation and deforestation. 
The most decisive factor for the successive Agroforestry is the choice of suitable useable tree/shrub species. Nitrogen fixing (legume) tree/shrub species are found to get popularity because of their fast growth, reducing fertilizer needs and coppicing behavior [9]. However, this will be effective if the right species planted in the right place as their adaptability potential strongly dependent up on the local climatic conditions and soil characteristics [4, 10]. This has pointed that, prior planting of any tree/shrub species in a given agroecology there is always the need of conducting a field trials on the suitability of the species for a particular site focusing on their adaptability and growth performance.

In many parts of Ethiopia, studies on adaptability and growth performance of tree/shrub species have been conducted $[4,5]$. However, in Dello-menna district of Bale zone, southeast Ethiopia, such experiments have not been yet conducted. This has been resulting that, plantation effort which has been undertaken by different stakeholder in the area to be restricted on a narrow range of tree/shrub species. Hence, this calls the introduction and evaluation of more alternative tree/shrub species via test of trial so as to diversify the options available and reduce the risks of over dependency on fewer species. The species may also offer an opportunity to develop better productive agroforestry land use system, importantly to solve the continuum soil degradation problem of the area. In realizing this, study was planned and undertaken with an objective of evaluating the adaptability potential of nitrogen fixing tree/shrub species in the study area.

\section{Materials and Method}

\subsection{Description of the Study Area}

The experiment was conducted at Sinana Agricultural Research sub sites of Cirri found in Dello-menna district of Bale zone, southeast Ethiopia. Geographically, Cirri research subsite located at $6.405 \mathrm{~N}$ and $39.782 \mathrm{E}$. The altitude of the district ranges within 1000 - 2500 meters above sea level. The rainfall pattern in the area is the bimodal type, that is, middle of March to end of May (short rain season) and September to October (the main rainy season). Annual rainfall ranges within $700-1200 \mathrm{~mm}$. The average temperature for Dello-menna is $18^{\circ} \mathrm{C}$ whereas the soil type is dominantly clay Niti-sol $[2,12]$.

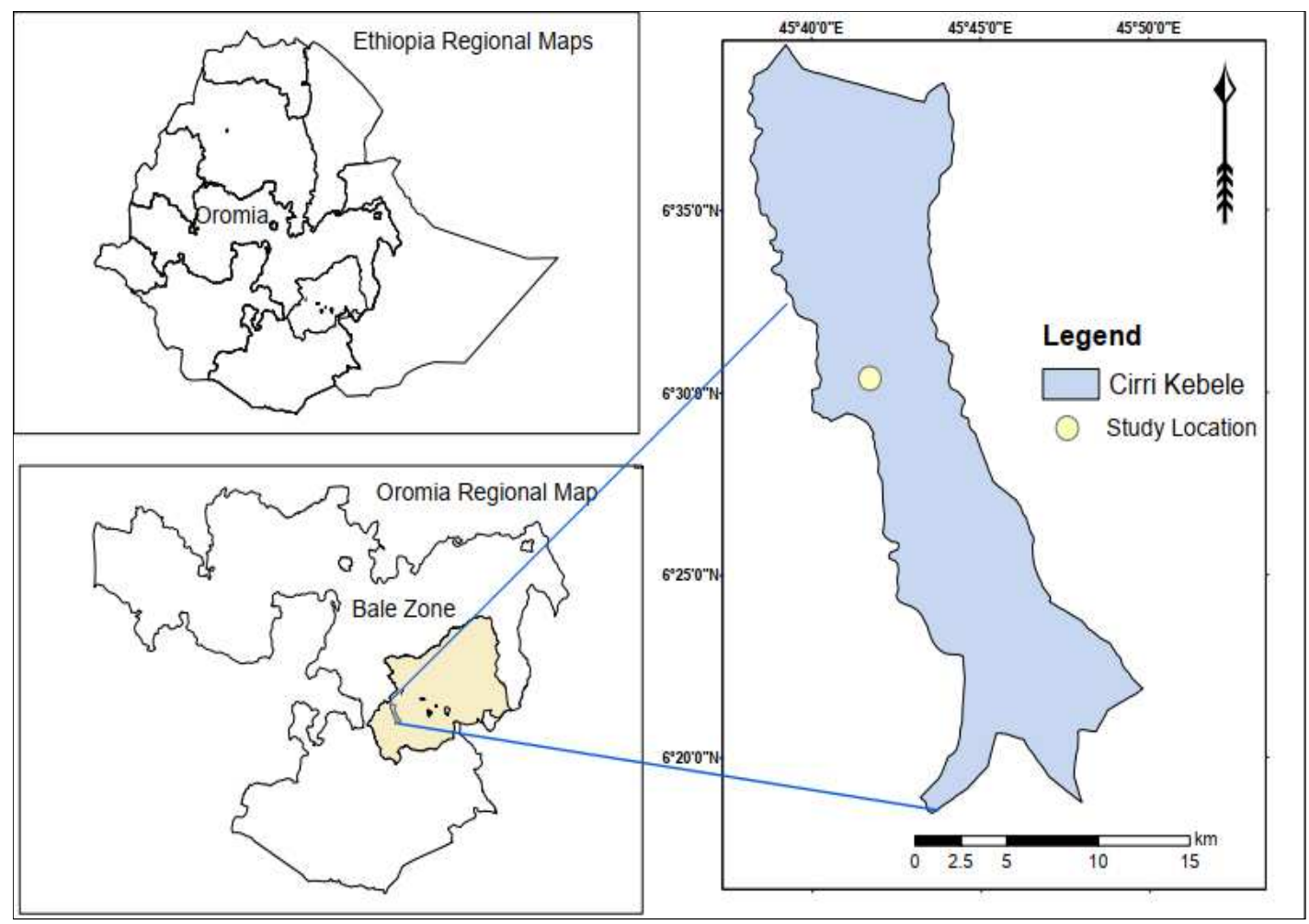

Figure 1. Location of the study area.

\subsection{Treatments and Experimental Procedure}

Six nitrogen fixing tree/shrub species namely; Cajanus cajan, Gliricidia sepium, Calliandra calothyrsus, Flemingya macrophylla, Sesbania sesban and Lucaena leucocephela are used. The seeds of the species were obtained from International livestock Research Institute (ILRI) of Ethiopia, which is located in Addis Ababa. In doing so the seeds were sown at chiri nursery site there by using a polythene tube size of $10 \mathrm{~cm}$ and potting mixture of 3:2:1 (forest, local and sandy soil). Initially the seedlings were raised under $60 \%$ of shade netting. However, in the meantime shading and watering frequency reduced as the seedlings grew. Even, the shade was completely removed a few days prior to planting in the field trial, in order to harden off. Finally, seedlings were transplanted and installed to the field trial by using RCBD design with three replications with a plot size of $8 \mathrm{~m} \times 6 \mathrm{~m}$ for each species. The spacing between plants was $2 \mathrm{~m} \times 2 \mathrm{~m}$ 
consisting of 12 plants over a single plot.

\subsection{Data Collection and Statistical Analysis}

The necessary growth-performance evaluating data parameters were collected. Survival rate, height and root collar diameter were the three parameters, which are considered for each species. Survival count was made for the whole tree/shrub species found in a plot (12 plants/plot), whereas for the remaining parameters about 6 trees are used as data source. Heights were measured using meter tape and/or graduated stick depending on the height of the trees. Likely, diameter (RCD) is measured by meter tape and caliper. Finally, the collected data were summarized and analyzed by using GenStat (15 $5^{\text {th }}$ ed.) and Microsoft Excel computerized programs.

\section{Results and Discussion}

\subsection{Survival Rate}

Results obtained from the study show that, except the first year a significant difference $(p<0.05)$ was reported for the survival rate of the species (table 1 ). During the $2^{\text {nd }}$ and $3^{\text {rd }}$ years of study period, Flemingya macrophylla, Sesbania sesban, and Cajanus cajan and Gliricidia sepium attain the highest mean values ranging from 83.33 to 100 . This infers the condition of the study area matched well with the environmental requirement of these species.

Table 1. The mean of survival rate of the species over the years of experimental period.

\begin{tabular}{|c|c|c|c|c|}
\hline Species & Year I & Year II & Year III & Total mean \\
\hline Cajanus cajan & $97.22^{\mathrm{a}}$ & $97.22 \mathrm{c}$ & $94.63^{c}$ & $96.36^{\mathrm{b}}$ \\
\hline Flemingya macrophylla & $100.00^{\mathrm{a}}$ & $100^{\mathrm{c}}$ & $100^{\mathrm{c}}$ & $100^{\mathrm{b}}$ \\
\hline Calliandra calothyrsus & $83.89^{\mathrm{a}}$ & $52.78^{b}$ & $11.11^{\mathrm{a}}$ & $49.26^{\mathrm{a}}$ \\
\hline Lucaena leucocephela & $83.33^{\mathrm{a}}$ & $16.66^{\mathrm{a}}$ & $13.89^{\mathrm{a}}$ & $37.96^{\mathrm{a}}$ \\
\hline Glericidia sepium & $97.22^{\mathrm{a}}$ & $91.66^{c}$ & $83.33^{b}$ & $90.74^{b}$ \\
\hline Sesbania sesban & $10000^{\mathrm{a}}$ & $97.22^{c}$ & $96.14^{\mathrm{c}}$ & $97.89^{b}$ \\
\hline $\operatorname{LSD}(p<0.05)$ & 25.46 & 26.06 & 9.52 & 21.10 \\
\hline
\end{tabular}

N/B: Means in columns with the same letters are not significantly different, $\mathrm{LSD}=$ Least significant difference

Against to this Calliandra calothyrsus and Lucaena leucocephela had the lowest survival rates over the entire experimental period. The lower survival rates of Lucaena leucocephela and $C$. calothyrsus attribute to their suitability for fodder production. As result of this fact the seedlings of these two species were adversely attacked by wild animals, namely: by antelope and buck at the night time of experimental period.

\subsection{Height Growth}

Analysis of variance revealed that variations in height among the species was considerably $(\mathrm{P}<0.05)$ variable over the years of study period (table 2). As results reported, plant height of Sesbania sesban was the tallest closely followed by Flemingya macrophylla and Cajanus cajan. This is in line with [3], who found superior performance of Sesbania sesban as compared to other species. Other authors [13] also reported better growth performance of Sesbania as compared to Lucaena, Calliandra and Chamaecystisus in Rwanda. This might be attributed to environmental requirement of the species and/or their genetic superiority.

Table 2. Mean of plant height growth (cm) as influenced by species type over the years of study period.

\begin{tabular}{lllll}
\hline Species & Year I & Year II & Year III & Total mean \\
\hline Cajanus cajan & $218.10^{\mathrm{b}}$ & $227.30^{\mathrm{c}}$ & $242.20^{\mathrm{c}}$ & $229.20^{\mathrm{bc}}$ \\
Flemingya macrophylla & $150.0^{\mathrm{ab}}$ & $244.00^{\mathrm{c}}$ & $222.00^{\mathrm{c}}$ & $199.80^{\mathrm{ab}}$ \\
Calliandra calothyrsus & $62.50^{\mathrm{a}}$ & $70.00^{\mathrm{a}}$ & $37.10^{\mathrm{a}}$ & $186.90^{\mathrm{ab}}$ \\
Lucaena leucocephela & $72.30^{\mathrm{a}}$ & $107.70^{\mathrm{ab}}$ & $38.20^{\mathrm{a}}$ & $111.10^{\mathrm{a}}$ \\
Glericidia sepium & $50.50^{\mathrm{a}}$ & $133.00^{\mathrm{b}}$ & $115.40^{\mathrm{b}}$ & $99.60^{\mathrm{a}}$ \\
Sesbania sesban & $485.90^{\mathrm{c}}$ & $423.30^{\mathrm{d}}$ & $596.00^{\mathrm{d}}$ & $396.60^{\mathrm{c}}$ \\
LSD $(\mathrm{p}<0.05)$ & $108.6^{\mathrm{a}}$ & $51.69^{\mathrm{a}}$ & $46.22^{\circ}$ & 168.70 \\
\hline
\end{tabular}

N/B: Means in columns with the same letters are not significantly different, $\mathrm{LSD}=$ Least significant difference

\subsection{Root Collar Diameter}

Significant variation $(\mathrm{p}<0.05)$ in root collar diameter growth is also reported among the studied species (table 3 ). Consistent to the observation made for plant height, the maximum root collar diameter was measured for $S$. sesban followed by $F$. macrophylla and $C$. cajan, the former being significantly higher than the latter two over the entire experimental period.

Table 3. Mean of root collar diameter (cm) as influenced by species type over the years of study period.

\begin{tabular}{lllll}
\hline Species & Year I & Year II & Year III & Total mean \\
\hline Cajanus cajan & $2.96^{\mathrm{b}}$ & $5.32^{\mathrm{bcd}}$ & $6.36 \mathrm{c}$ & $4.88^{\mathrm{b}}$ \\
Flemingya macrophylla & $5.06^{\mathrm{c}}$ & $6.13^{\mathrm{d}}$ & $6.14^{\mathrm{c}}$ & $5.77^{\mathrm{c}}$ \\
Calliandra calothyrsus & $1.60^{\mathrm{a}}$ & $2.20^{\mathrm{a}}$ & $2.96^{\mathrm{a}}$ & $2.25 \mathrm{a}$ \\
Lucaena leucocephela & $2.12^{\mathrm{ab}}$ & $3.47^{\mathrm{a}}$ & $3.47^{\mathrm{a}}$ & $3.09^{\mathrm{a}}$ \\
Glericidia sepium & $3.65 \mathrm{~b}$ & $4.01^{\mathrm{bc}}$ & $5.08^{\mathrm{b}}$ & $4.25^{\mathrm{b}}$ \\
Sesbania sesban & $7.78^{\mathrm{d}}$ & $8.17^{\mathrm{e}}$ & $8.40^{\mathrm{d}}$ & $8.17^{\mathrm{d}}$ \\
LSD $(\mathrm{p}<0.05)$ & 1.270 & $1.67^{\mathrm{b}}$ & $0.97^{\mathrm{b}}$ & 0.91 \\
\hline
\end{tabular}

N/B: Means in columns with the same letters are not significantly different, $\mathrm{LSD}=$ Least significant difference

Results indicated that tree species having greatest root collar diameter were those, which grew tallest. Highly significant correlation $(\mathrm{r}=0.95, \mathrm{p}=0.001)$ was observed between height growth and root collar diameter development. Most of the tree and/or shrub species (about 83.3\%) having more height growth exhibited higher root collar diameter growth. Similarly, species with lower height growth had lower root collar diameter growth. Other finding also reported similar highest correlation between height growth and root collar diameter growth of tree/shrub species $[1,10]$.

\section{Summary and Conclusion}

The most decisive factor for the successive Agroforestry is the choice of suitable useable tree/shrub species. Nitrogen 
fixing (legume) tree and shrub species are found to get popularity because of their fast growth, reducing fertilizer needs and coppicing behavior. However, this will be effective if the right species planted in the right place as their adaptability potential strongly dependent up on the local climatic conditions and soil characteristics. With this general understanding, study was planned and conducted to evaluate the adaptability potential of six nitrogen fixing tree/shrub species in Dello-menna district of Bale zone, southeast Ethiopia. The species were; Cajanus cajan, Flemingya macrophylla, Gliricidia sepium, Sesbania sesban, Calliandra calothyrsus and Leucaena leucocephela.

The result revealed that the survival rate of Flemingya macrophylla was found to be the highest followed by Sesbania sesban and Cajanus cajan respectively. While Lucaena leucocephela and Calliandra calothyrsus showed poor survival rate. The lower survival rates of Lucaena leucocephela and Calliandra calothyrsus were attributed to their suitability for fodder production as both were adversely attacked by wild animals during the study period. Flemingya macrophylla, Sesbania sesban, Gliricidia sepium and Cajanus cajan attain the highest mean values in height and root collar diameter while Calliandra calothyrsus and Lucaena leucocephela had the lowest values. Overall, Flemingya macrophylla, Cajanus cajan, Gliricidia sepium and Sesbania sesban species have shown the better vigorous growth performance in the study area. Hence, the integration of these tree/shrub species into any of tree-based land use system will be beneficial either to get their environmental or economic function. However, evaluation of their contribution to soil fertility improvement and crop yield needs to be further investigated as this may insights to know their nutrient provision potential while integrated together with annual and/or perennial plants in agroforestry land use systems.

\section{References}

[1] Abebe Yadessa, Diriba Bekere and Taye Bekele, 2000. Growth performance of different multipurpose tree and shrub species at Bako, Wester Oromia. Pp. 177-186. In: Proceedings of the fifth conference of the Ethiopian society of soil science. March 30-31, 2000, Addis Ababa, Ethiopia.

[2] Abiyot Molla and Gonfa Kewessa, 2015. Woody Species Diversity in Traditional Agroforestry Practices of Dellomenna District, Southeastern Ethiopia: Implication for Maintaining Native Woody Species. International Journal of Biodiversity; Article ID 643031.
[3] Betre Alemu, Tekalign Mamo, Alemayehu Zemedie and Ebrahim Ahmed, 2000. Promising Multipurpose tree species and their response to landform on highland vertisols at Chefe Donsa, central highlands of Ethiopia. Pp. 145-155. In: Proceedings of the fifth conference of the Ethiopian society of soil science. March 30-31, 2000, Addis Ababa.

[4] Getahun Yakob, Kebede Gizachew, Anteneh Fekadu, Kefyalew Kassa, 2017. Growth performance of some multipurpose tree species around the homesteads in Gimbo District, Southwestern Ethiopia. Journal of Agriculture, Forestry and Fisheries. Vol. 6, No. 1, pp. 1-5. Doi: 10.11648/j.aff.20170601.11.

[5] Musa Abdella and Bira Cheneke, 2020. Adaptation and Growth Performance of Multipurpose Tree Species under Erer Dodota condition, Harari Region, Ethiopia. International Journal of Environmental Sciences \& Natural Resources; vol. 24 (1): 556130. Doi: 10.19080/IJESNR.2020.23.556130.

[6] Nair, 1993. An introduction to agroforestry. Kluwer Academic Publisher, Dordrecht, Netherland. pp. 499.

[7] Paudel Ekananda, Dossa, G. O., Philip Beckscha, Jianchu Xu and Rhett D. Harrison, 2015. Quantifying factors affecting leaf litter decomposition across a tropical forest disturbance gradient. Journal of Ecosphere, 6 (12): 267.

[8] Reta Hailu, 2016. Population dynamism and agrarian transformation in Ethiopia. African Journal of Agricultural Research, 11 (39): 3863 - 3879.

[9] Sarmin, Miah and Mohd Hasmadi, 2014. Comparative growth performance of four multipurpose tree species in different containers under nursery condition at Bangabandhu Sheikh Mujibur Rahman Agricultural University, Gazipur, Bangladesh. Journal of agroforestry and Environment, 8 (2): $43-48$.

[10] Tilahun Chibsa, Motuma Didita, Yifru Abera and Mengistu Yadessa, 2006. Screening of Multipurpose tree and shrub species for adaptability and growth performance at Sinana, Southeastern Ethiopia. Ethiopian Journal of Natural Resource, vol. 8 (2): pp. 271-279.

[11] Wondmagegn Bekele, 2017. Decomposition and Nutrient Release Pattern of Three Agroforestry Shrub Species Foliage at Dello-menna District of Bale Zone, Southeast Ethiopia. Msc. Thesis, Haramaya University, Haramaya.

[12] Wondmagegn Bekele and Lisanework Nigatu, 2019. Chemical composition of green foliage biomass of three agroforestry shrub species grown in Dello-menna district of Bale Zone, southeast Ethiopia. International Journal of Agroforestry and Silviculture: vol. 7 (1), pp. 1-4.

[13] Yamoah, C., Grosz, R. and Nizeyimana, E., 1989. Early growth of alley shrub species in the highland regions of Rwanda. Journal of Agroforestry systems, vol 9 (2): pp. 171184. 